\title{
BMJ Global Health Improving hospital death certification in Viet Nam: results of a pilot study implementing an adapted WHO hospital death report form in two national hospitals
}

\author{
Merrilyn Walton, ${ }^{1}$ Reema Harrison, ${ }^{1}$ Anna Chevalier, ${ }^{2}$ Esmond Esguerra, ${ }^{1}$ \\ Dang Van Duong, ${ }^{3}$ Nguyen Duc Chinh, ${ }^{4}$ Huong Giang ${ }^{3}$
}

To cite: Walton $M$

Harrison R, Chevalier A, et al. Improving hospital death certification in Viet Nam: results of a pilot study implementing an adapted WHO hospital death report form in two national hospitals. BMJ Global Health 2016;1:e000014

doi:10.1136/bmjgh-2015000014

Received 21 November 2015 Revised 29 February 2016 Accepted 24 March 2016

CrossMark

${ }^{1}$ School of Public Health, University of Sydney, Sydney, Australia

${ }^{2}$ Injury Prevention Unit, The George Institute of Global Health, University of Sydney, Sydney, Australia

${ }^{3}$ Department of Planning, Bach Mai Hospital, Hanoi, Vietnam

${ }^{4}$ Department of Planning, Viet Duc Hospital, Hanoi, Vietnam

\section{Correspondence to}

Dr Reema Harrison;

reema.harrison@sydney.

edu.au

\section{ABSTRACT}

Background: Viet Nam does not have a system for the national collection of death data that meets international requirements for mortality reporting. It is identified as a 'no-report' country by the WHO. Verbal autopsy reports are used in the community but exclude deaths in hospitals.

Methods: This project was undertaken in Bach Mai National General Hospital and Viet Duc Surgical and Trauma Hospital in Viet Nam from 1 March 2013 to 31 March 2015. In phase 1, a modified hospital death report form, consistent with the International Statistical Classification of Diseases and Related Health Problems, 10th Revision, was developed. Small group training in use of the report form was delivered to 427 doctors. In phase two, death data were collected, collated and analysed. In phase three, a random sample $(7 \%)$ of all report forms was checked for accuracy and completeness against medical records.

Findings: During the 23 months of the study, 3956 deaths were recorded. Across both hospitals, 222 distinct causes of deaths were recorded. Traumatic cerebral oedema was the immediate cause of death ( $15 \%$ of cases, $575 / 3956$ patients), followed by septic shock $(13 \%, 528 / 3956)$, brain compression $(11 \%$, $416 / 3956)$, intracerebral haemorrhage (8\%, 336/3956) and pneumonia $(5 \%, 186 / 3956) ; 67 \%(2639 / 3956)$ of patients were discharged home to die and 33\% (1314/ 3956) of deaths were due to a road traffic accident, or injury at home or at work.

Conclusions: This study confirms the viability of implementing a death report form system compliant with international standards in hospitals in Viet Nam and provides the foundation for introducing a national death report form scheme. These data are critical to comprehensive knowledge of causes of death in Viet Nam. Death data about patients discharged home to die is presented for the first time, with implications for countries where this is a cultural preference.

\section{INTRODUCTION}

Apart from death reporting for legal purposes, mortality data are critical to

\section{Key questions}

What is already known about this topic?

- The death reporting system in Vietnam is currently undeveloped and unable to meet international standards.

- Reliance on verbal autopsy (community) and verification from health professionals (hospital government report) produces death data of varying quality and accuracy.

- Most people in Vietnam die at home but the WHO hospital death certificate does not capture data regarding those discharged home to die and is therefore unsuitable for many countries.

\section{What are the new findings?}

- Most hospital patients with a prognosis of death $(67 \%)$ were discharged home to die.

- The hospital death report form piloted was a viable approach to collect data on causes of pre and in-hospital deaths and probable causes of death for those discharged home to die.

- Brain injuries were the most common immediate causes of death in the participating hospitals. The most common were traumatic cerebral oedema, brain compression and intracerebral haemorrhage, accounting for $36 \%$ of deaths.

- Road traffic accident, or injury at home or at work, was responsible for $33 \%$ of deaths.

Recommendations for policy

- Accurate death data are essential for health systems resource planning.

- Comparable data mean that, regarding causes of death, Vietnamese data can be analysed with international death data from other countries.

- Health professionals in Vietnam must receive regular training in the use of International Statistical Classification of Diseases (ICD) coding to accurately and effectively complete hospital death report forms. 
understand the underlying health of a population, including data about deceased persons' social and economic welfare. ${ }^{12}$ Mortality data can identify the leading causes of deaths in a population and provide evidence to enable prioritising of disease prevention efforts. ${ }^{3} 4$ Such data assist governments to allocate scarce resources for epidemiological research. ${ }^{5}$

The United Nations (UN) and WHO have long advocated for countries to develop a system for civil (birth and death) registration. ${ }^{6}$ Compiling accurate annual mortality data requires a standardised and sustainable system for recording causes of death in the population. In 1974, the WHO established the International Institute for Vital Registration and Statistics, to assist member countries in developing a standardised cause of death recording and coding system. ${ }^{3}$ The WHO cause of death medical report form was developed to accommodate the International Statistical Classification of Diseases and Health Related Problems (ICD-10). This new format included reporting underlying medical conditions in chronological sequence from the immediate cause of death to other diseases and conditions that may not directly be associated with the death. ${ }^{7}$

Viet Nam, with a population of 93.5 million people, relies on the Ministry of Justice Vital Registration and Primary Vital Record system for mortality data. ${ }^{8}$ The data captured by these two agencies remain underdeveloped, with Vietnamese mortality data rarely being reported to the WHO. ${ }^{9}$ The General Statistics Office of Viet Nam reports three mortality databases for children; these provide limited data. In Viet Nam, the high volume of deaths that occur outside medical facilities after patients are discharged home is a challenge when utilising internationally recognised approaches to the collection of hospital mortality data. ${ }^{5} 10$ Prior to this study, death data in the community have been collected using a method called Verbal Autopsy (VA) and deaths at hospitals have been recorded on a government Death Notification Form that does not record reliable clinical information.

$\mathrm{VA}$ is the process of interviewing close family members and/or friends of the recently deceased to determine the cause of death. Death data statistics derived from VA reports rarely meet international requirements for reporting specified conditions, including maternal and child health, and HIV/AIDS. ${ }^{11}{ }^{12}$ Reliance on VA for data about causes of death is common in many countries in South East Asia, where civil registration systems are underdeveloped. ${ }^{13}{ }^{14}$ Currently, VA is the only system of recording deaths in Viet Nam that aligns with cultural practices and accounts for those who choose to die at home. The quality and completeness of the information collected via VA vary; lack of medical training of those completing the forms may be one factor for the low quality of the data. ${ }^{10} 13$

In a 2003 VA study in the Bavi District, Viet Nam, the main cause of death was cardiovascular disease followed by infections and injuries (eg, traffic accidents, injuries occurring within the home, drowning, etc) ${ }^{13}$ Another 2010 VA study of mortality patterns in Viet Nam identified leading causes of death for both sexes to be cerebrovascular disease, followed by transport accidents and chronic lower respiratory diseases. ${ }^{15} 16$

In addition to VA, all hospitals in Viet Nam are required by the Ministry of Health $(\mathrm{MoH})$ to complete a Death Notification form. This form does not allow recording of detailed information about the immediate and underlying causes of death. In some cases, death data from Vietnamese hospitals are provided to a trauma registry as well as registries for maternal, neonatal and child deaths, but this is not routine and these data are often incomplete. ${ }^{11}$ A 2010 review of mortality data in Viet Nam identified a range of structural and social barriers to the collection/accuracy of civil and vital statistics, highlighting that the death notification form submitted by hospitals has minimal information about the cause of death and capacity to record neither immediate cause of death, nor underlying and contributory causes of death. $^{11}$

This study is the first to provide data about the immediate causes of deaths of hospital patients in Viet Nam and to identify the causes of death of those discharged home from hospital to die. Detailed cause of death information at a population level is useful for research and health systems analysis, and in particular to support the $\mathrm{MoH}$ in healthcare resource planning. A standardised hospital death report form system was introduced in two of the largest hospitals in Viet Nam. The death report form system was designed to comply with WHO requirements in relation to coding diseases and conditions according to the ICD-10. A main barrier to implementing a WHO compliant hospital death report form system in Viet Nam relates to the cultural preference of people to die at home surrounded by family. We addressed this by modifying the WHO death report form to include information about patients discharged home to die who are (A) diagnosed with imminent death or (B) discharged home to die diagnosed with an uncertain prognosis regarding when they will die.

\section{METHOD \\ Setting}

The death report form system was implemented at Bach Mai National General Hospital (1400 beds) and Viet Duc Surgical and Trauma Hospital (500 beds). These hospitals capture different patient groups, as most trauma patients are directed to Viet Duc, whereas Bach Mai admits patients with a greater range of diseases and conditions. Both are located in the national capital, Hanoi, which is situated in North Viet Nam. These hospitals were selected as they are the main tertiary teaching hospitals for the city and northern rural provinces, and cover general medicine, all subspecialties, surgery and trauma. 


\section{Phase 1: Preparation}

The final WHO death report form, approved by the hospitals' directors and research advisory committees, was modified to include the following additional items: discharged home to die, imminent death; discharged home to die, uncertain time of death; and hospital acquired infection. See figure 1 for the English version of the existing death notification form and the modified WHO death report form.

The modified death report form was piloted to ensure it was culturally acceptable, and easy to comprehend and use. Training resources were developed in English and translated into Vietnamese. A train-the-trainer programme was delivered to senior doctors and managers in both hospitals. Bach Mai employs 470 doctors and Viet Duc employs 302 doctors-it was not feasible or sustainable to train every doctor. Therefore only the senior doctors were trained; 307 senior doctors were trained in $2 \mathrm{~h}$ workshops of 20 participants per workshop. A train-the-trainer method was used as well as the development of a training manual for senior doctors to train other doctors in their departments. The ICD-10 coding manual, Level 3, was made available in different wards and departments. Training included the benefits of collecting nationwide mortality statistics, how and when to complete a death report form (within $48 \mathrm{~h}$ of

Medical Report of Cause of Death in Hospital Research

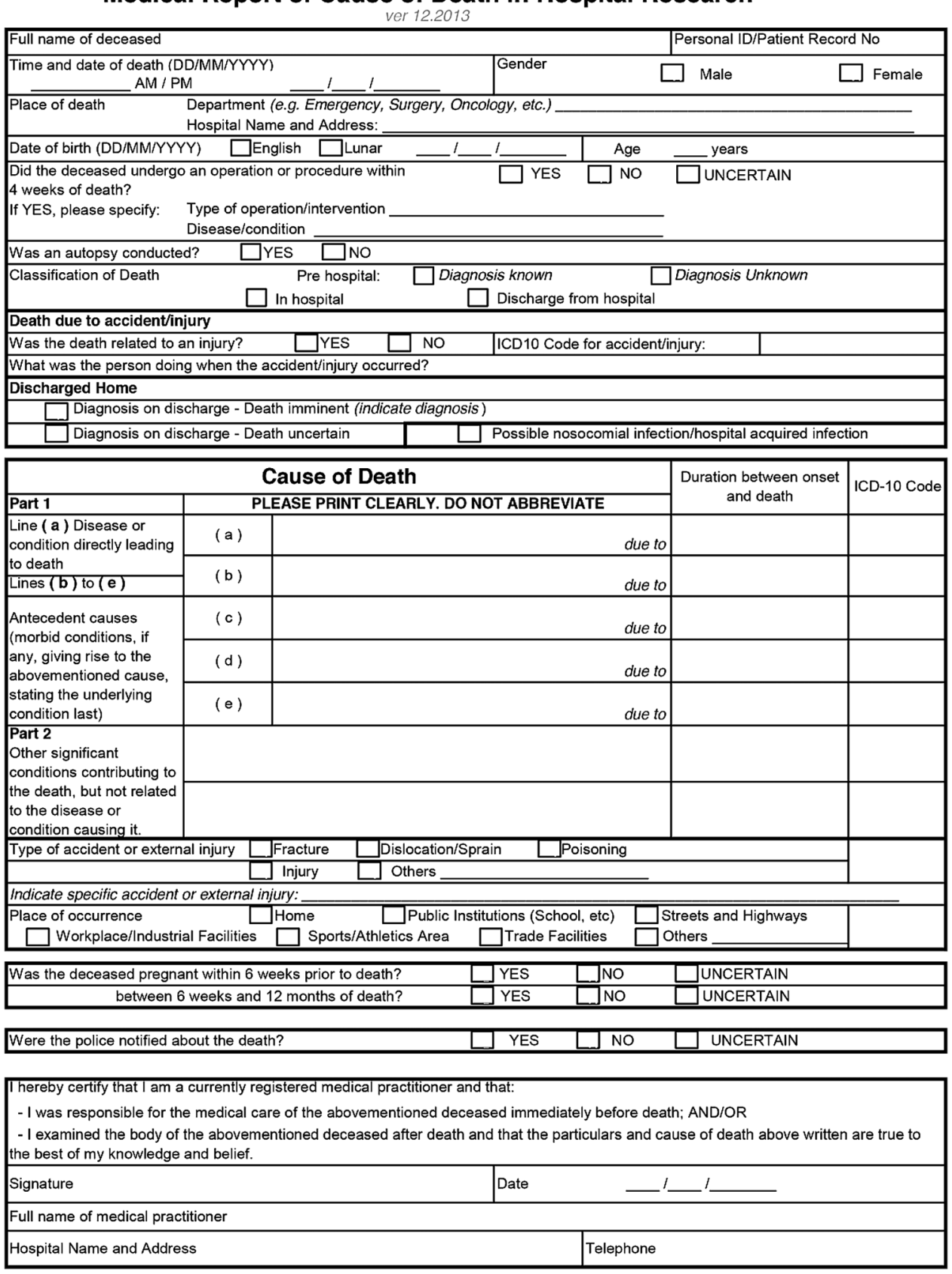

Figure 1 Example of the adapted death report form-English version. 
death), use of the ICD-10 codes, how to practise completing the report form using case studies, information about storage of completed report forms and protocols around accessing the data.

\section{Phase 2: Implementation}

The hospital death report form system was started on 1 May 2013. While data collection continues, the data presented in this analysis includes deaths recorded in the 23 months until the end of March 2015. Within each hospital, the Department of Planning assumed responsibility for data collection, and checking for accuracy and completion. Senior hospital doctors were responsible for the completion of the forms and were required to sign off on each form. In addition, the Department of Planning staff checked completion of forms as well as following up on departments. Each Department of Planning used a password-protected computer to secure death information collected for the project, with only authorised staff given access to the computer and the death database. The Departments produced monthly reports, which were sent to the research team at the University of Sydney, where they were collated and underwent a further check for accuracy and completeness. Feedback, including areas for improvement, was provided on a monthly basis to the hospital doctors and managers. The lead investigator also gave biannual presentations of the data, provided regular updates to the hospital doctors and managers, and also presented them at hospital grand rounds.

\section{Phase 3: Evaluation}

A random sample of $7 \%(280 / 3956)$ of all death reports completed between March 2013 and May 2015 was assessed against the patients' medical records, to establish the accuracy of the immediate cause of death diagnosis (ICD-10 coding), the underlying conditions, and timeliness and completeness of the data recorded on the report forms. Two reviewers completed the technical evaluation (EE and $\mathrm{RH}$ ). Each reviewer was supported by a clinician from the hospital who identified and translated the information required from the medical records. A data extraction protocol and a data extraction form were developed. Each reviewer entered the data from the medical record into this form. Data relating to each item in the new death certificate were extracted. The following patient information was extracted: name, age, gender, date of death, department of death, whether an operation occurred, whether an autopsy was conducted, whether death resulted from an accident, where the accident occurred, ICD coding of the accident, healthcareassociated infection-related deaths, pregnant women deaths, immediate cause of death, underlying causes of death and the ICD-10 codes for causes of death. The evaluation found basic patient identification and death information were fully and consistently completed in the new death report forms. However, doctors found the complex identification of underlying causes of death and ICD-10 coding challenging. For this reason, the paper reports data on the immediate cause of death only.

\section{ANALYSIS}

A death report database recorded death information using Filemaker Pro. Data were analysed using the Statistical Package for the Social Sciences (SPSS V.21). Descriptive statistics were used to present information about the sample characteristics and calculate frequencies of the immediate causes of deaths reported. Inferential statistics were used to compare the growth in the number of deaths reported annually before and after the new report form was implemented.

\section{RESULTS}

Death report form data were collected over 23 months from 1 May 2013 to 31 March 2015, during which time 3966 deaths were recorded. Ten reports did not include complete death data and were excluded, leaving $99.7 \%$ (3956/3966) of the death report forms for analysis. Of these, $71 \%$ (2825/3956) were male, with $40 \%$ (1567/ 3956) aged $35-59$ years, $21 \%(846 / 3956)$ aged $60-74$ years, $13 \%(532 / 3956)$ aged $75-89$ years and $1 \%$ (58/ 3956) aged 90 years and older. The ages of recorded deaths were higher at Bach Mai than at Viet Duc hospital. Table 1 contains a summary of the characteristics of the recorded deaths.

In the 12 months prior to this study, 446 Death Notification forms had been submitted to the $\mathrm{MoH}$ from Bach Mai Hospital, being an average of 37 reported deaths per month. ${ }^{17}$ During the first 12 months of this study, 1033 death report forms were submitted to this hospital; an average of 86 reported deaths per month $(38 \%, 394 / 1033$ were discharged home to die). The growth in the number of deaths reported annually was statistically significant $(\mathrm{t}=-7.45$, $\mathrm{df}=11, \mathrm{p}<0.001)$. Figure 2 depicts a comparison of the death rates reported over 12 months.

Most patients died either before reaching hospital, or in-hospital, or were discharged home to die from the emergency department in both hospitals (68\%; 2675/ 3956. Bach Mai 69\%; 1610/2340. Viet Duc 66\%; 1065/ 1616). Viet Duc patients most commonly died within the intensive care unit $(19 \% ; 300 / 1616)$ and the neurosurgery department $(11 \% ; 174 / 1616)$. In Bach Mai, most died within the cardiology department $(10 \% ; 239 / 2340)$ and intensive care unit $(6 \% ; 132 / 2340)$.

\section{Immediate causes of deaths}

Overall, 222 immediate causes of death were recorded across both hospitals; 169 different causes at Bach Mai and 75 at Viet Duc. Traumatic cerebral oedema was the immediate cause in $15 \%(575 / 3956)$ of all recorded deaths, followed by septic shock in 13\% (528/3956), brain compression in $11 \%(416 / 3956)$, intracerebral 
Table 1 Characteristics of reported deaths at Bach Mai and Viet Duc Hospitals (May 2013 to March 2015)

\begin{tabular}{|c|c|c|c|}
\hline Deaths recorded & $\begin{array}{l}\text { Bach Mai } \\
\text { Frequency } \\
(\%)\end{array}$ & $\begin{array}{l}\text { Viet Duc } \\
\text { Frequency } \\
(\%)\end{array}$ & $\begin{array}{l}\text { Total } \\
\text { Frequency } \\
(\%)\end{array}$ \\
\hline \multicolumn{4}{|l|}{ Gender } \\
\hline Male & 1577 (67) & $1248(77)$ & $2825(71)$ \\
\hline Female & 763 (33) & $368(23)$ & $1131(29)$ \\
\hline \multicolumn{4}{|l|}{ Age } \\
\hline Under 28 days & $47(2)$ & $1(<1)$ & $48(1)$ \\
\hline Under 5 years & $36(2)$ & $20(1)$ & $56(1)$ \\
\hline $5-14$ years & $9(<1)$ & $33(2)$ & $42(1)$ \\
\hline 15-34 years & $233(10)$ & $562(35)$ & $795(20)$ \\
\hline $35-59$ years & 918 (39) & $649(40)$ & $1567(40)$ \\
\hline $60-74$ & $636(27)$ & $210(13)$ & $846(21)$ \\
\hline $75-89$ & $416(18)$ & $116(7)$ & $532(13)$ \\
\hline $90+$ & $41(2)$ & $17(1)$ & $58(1)$ \\
\hline Unknown & $12(1)$ & $8(<1)$ & $20(1)$ \\
\hline \multicolumn{4}{|l|}{ Location of death } \\
\hline Prehospital & $222(9)$ & $41(3)$ & $263(7)$ \\
\hline In-hospital & $963(41)$ & $66(4)$ & $1029(26)$ \\
\hline Discharged home & $1153(49)$ & $1486(92)$ & 2639 (67) \\
\hline Unknown & $2(<1)$ & $23(1)$ & $25(1)$ \\
\hline \multicolumn{4}{|l|}{ Department } \\
\hline Emergency & $1610(69)$ & $1065(66)$ & $2675(68)$ \\
\hline Intensive care & $132(6)$ & $300(19)$ & $432(11)$ \\
\hline Cardiology & 239 (10) & $1(<1)$ & $240(6)$ \\
\hline Neurosurgery & NA & $174(11)$ & $174(4)$ \\
\hline Poison control & $127(5)$ & NA & $127(3)$ \\
\hline Paediatrics & $94(4)$ & NA & $94(2)$ \\
\hline $\begin{array}{l}\text { Infectious } \\
\text { diseases }\end{array}$ & $69(3)$ & $2(<1)$ & $71(2)$ \\
\hline Other & $65(3)$ & $70(4)$ & $135(3)$ \\
\hline Unknown & $4(<1)$ & $4(<1)$ & $8(<1)$ \\
\hline \multicolumn{4}{|c|}{ Death related to an external injury } \\
\hline Yes & $133(6)$ & $1181(73)$ & $1314(33)$ \\
\hline No & $2203(94)$ & $407(25)$ & $2610(66)$ \\
\hline Unknown & $4(<1)$ & $28(2)$ & $32(<1)$ \\
\hline \multicolumn{4}{|c|}{ Operation in last 4 weeks } \\
\hline Yes & $45(2)$ & $479(30)$ & $524(13)$ \\
\hline No & $2293(98)$ & $1137(70)$ & $3430(87)$ \\
\hline Unknown & $2(<1)$ & $0(0)$ & $2(<1)$ \\
\hline Total & $2340(100)$ & $1616(100)$ & $3956(100)$ \\
\hline
\end{tabular}

NA, not applicable.

haemorrhage in $8 \%(336 / 3956)$ and pneumonia in $5 \%$ $(186 / 3956)$.

While septic shock was the second most recorded immediate cause of death for the combined hospitals, at Bach Mai Hospital it was the most frequently recorded cause of death $(16 \%, 380 / 2340)$, followed by intracerebral haemorrhage (14\%, 335/2340). At Bach Mai Hospital, the immediate cause of death was unspecified in 6\% (149/2340) of cases. The most frequently reported cause of death at Viet Duc Hospital was traumatic cerebral oedema $(36 \%, 575 / 1616)$ followed by compression of the brain $(26 \%, 416 / 1616)$. Table 2 contains a breakdown of the immediate causes of death.

\section{Discharged home to die}

Two-thirds $(67 \%, 2639 / 3956)$ of recorded deaths were patients diagnosed as facing imminent death and discharged home to die. The remaining third died while in $(26 \%, 1029 / 3956)$ or before reaching $(7 \%, 263 / 3956)$ hospital. The percentage of patients diagnosed with imminent death and discharged home to die was substantially higher for those presenting at Viet Duc (92\%, 1486/1616) compared with Bach Mai Hospital (49\%, $1153 / 2340)$. Of patients who died as a result of an injury $(33 \% ; 1314 / 3956)$, significantly more were discharged home $(45 \%, 1174 / 2639)$ than those who died pre or in-hospital $(11 \%, 140 / 1292) \quad(\mathrm{t}=130, \mathrm{df}=1313$, $\mathrm{p}<0.001)$. A slightly higher proportion of males $(73 \%$, 1922/2639) were discharged home to die than the proportion who died before or while in hospital $(68 \%$, $878 / 1292)$. Only $11 \%(289 / 2639)$ of those discharged home to die were over 75 years old compared to $23 \%$ $(300 / 1292)$ of those who died before reaching or in-hospital. Characteristics of those discharged home to die are provided in table 3.

The probable cause of pending deaths identified among those discharged home to die was traumatic cerebral oedema, accounting for $21 \%(555 / 2639)$ of these deaths, followed by brain compression $(15 \%, 409 / 2639)$ and septic shock $(13 \%, 338 / 2639)$. The probable causes of pending deaths identified among those discharged home to die from Bach Mai were septic shock $(20 \%$, $233 / 1153)$, followed by intracerebral haemorrhage (20\%, 234/1153), intentional self-poisoning (9\%, 99/ $1153)$ and pneumonia $(7 \%, 79 / 1153)$. The immediate probable causes of death for those discharged home to die are provided in table 4.

\section{External injury as the cause of death}

A third of all recorded deaths $(33 \%, 1314 / 3956)$ were associated with an external injury. When examined by hospital, almost three-quarters $(73 \%, 1181 / 1616)$ of deaths recorded at Viet Duc involved an injury compared to only $6 \%(133 / 2340)$ of those recorded at Bach Mai. The majority of deaths involving an injury recorded at Bach Mai Hospital $(93 \%, 124 / 133)$ contained insufficient information to determine the type of injury, whereas for Viet Duc this accounted for $7 \%$ (83/1181) of recorded deaths involving an injury. Injuries resulting from road traffic accidents comprised 65\% (854/1314) of all injury-related deaths. Injuries from collisions involving motorcycles comprised $74 \%(630 / 854)$ of all reported deaths from injuries related to traffic accidents. The next most common incident causing injury was 
Figure 2 Monthly report of death at Bach Mai Hospital in the 12 months before and after the death certificate system was implemented (May 2012 to April 2014).

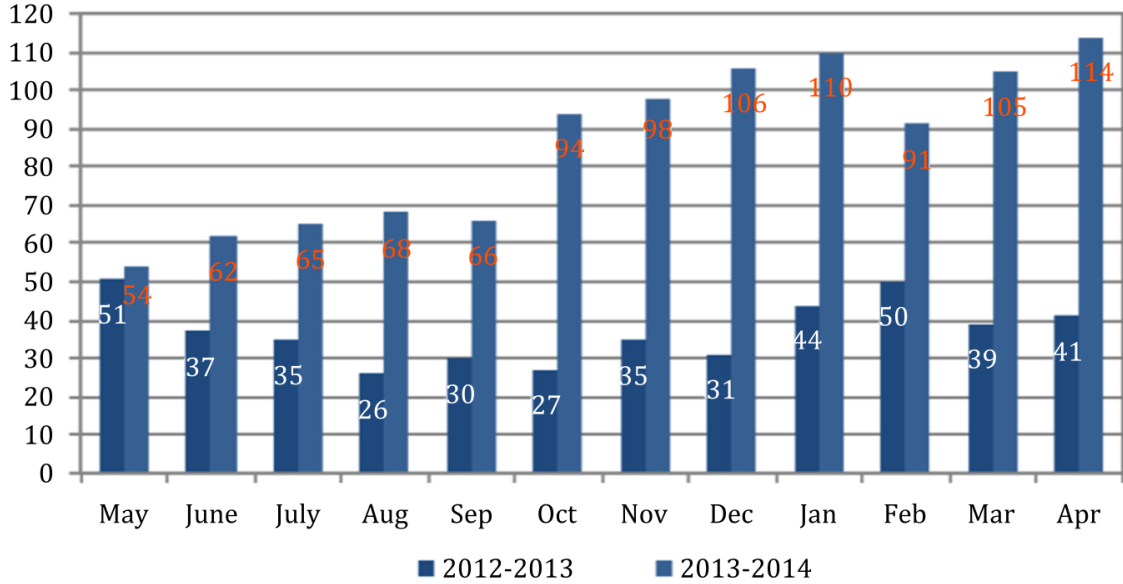

falls, comprising $7 \%(98 / 1314)$ of recorded deaths related to injuries. A higher proportion of male deaths were due to injury $(37 \%, 1036 / 2825)$ compared to female deaths $(25 \%, 278 / 1131)$. Table 5 contains the breakdown of injury-related deaths.

\section{Technical evaluation}

Basic patient identification and death information was consistently and fully completed in the new certificates; over $94 \%$ of the certificates had complete and accurate information about patient age, gender, date and time of death, department of death, location of death (home or hospital) and whether the patient had had an operation or an autopsy. Inconsistencies were evident in the more complex and analytical components of the certificate, which asked staff to capture immediate and underlying causes of deaths, and to code these death data using ICD-10 coding. The immediate cause of death was completed in almost every case $(99.6 \%)$, but the first underlying causes of death also lacked consistency with medical records in $52.9 \%$ of cases.

\section{DISCUSSION}

Information about the main causes of deaths in Viet Nam, beyond VA reports about deaths in the community, has previously been unavailable. Our findings show the leading causes of deaths to be traumatic cerebral oedema, septic shock and brain compression, with some differences between the two participating hospitals due to the nature of their patient populations. In Bach Mai Hospital, the leading three causes of deaths were septic shock, intracerebral haemorrhage and pneumonia, whereas in Viet Duc Surgical and Trauma Hospital, the leading causes of deaths were traumatic cerebral oedema, septic shock and brain compression; conditions often associated with trauma. The top three leading causes of deaths across both hospitals in our study are different to the main causes of deaths identified in the 2003 VA study (cardiovascular disease, infections, injuries) and 2010 VA study (cerebrovascular disease, injuries, chronic lower respiratory disease). ${ }^{13}{ }^{15}{ }^{16}$ One explanation for this is that those involved in traffic crashes and injuries, which occur in public spaces, are routinely transferred to a hospital whereas patients with other serious conditions may choose to not go to a hospital. Given the large proportion of people who are discharged home to die, our data suggest that admission to a hospital is often seen as a last resort for families; financial costs may be one consideration. Therefore, deaths associated with strokes and heart disease may occur more frequently in the community than in hospitals and do not appear as a main cause of hospital recorded death.

Similar to VA findings, a higher proportion of deaths were among males, despite a similar population ratio of males to females. ${ }^{16}$ A higher proportion of male deaths were also due to injury. Most patients died either before reaching, or in-hospital, or when discharged home from the emergency department, in both hospitals, reinforcing the fact that hospitals are often seen as a last resort when patients are in a critical stage of their illness.

\section{Discharged home to die}

This research demonstrates the majority of patients $(67 \%)$ were discharged home to die and many of these deaths were associated with trauma from an injury (45\%). Traumatic cerebral oedema was the main cause of pending deaths in Viet Duc and overall, with intracerebral haemorrhage and brain compression as the main causes of pending deaths in Bach Mai hospital. The inclusion of deaths of patients discharged home to die may, in part, explain the increased numbers of deaths reported when the new death report form was introduced. This cultural preference may be one reason why hospital death data in Viet Nam has previously been difficult to capture. The volume of patients discharged home demonstrates the importance of having a death data collection system that can capture information about these deaths in Viet Nam. However, there is a need for a verification system to confirm the causes of pending deaths and to ensure the accuracy of this data on death. 
Table 2 Immediate causes of deaths (May 2013 to March 2015)

\begin{tabular}{|c|c|c|c|c|}
\hline Immediate cause of death & $\begin{array}{l}\text { Bach Mai } \\
\text { Frequency (\%) }\end{array}$ & $\begin{array}{l}\text { Viet Duc } \\
\text { Frequency (\%) }\end{array}$ & $\begin{array}{l}\text { Total } \\
\text { Frequency (\%) }\end{array}$ & $\begin{array}{l}\text { ICD-10 } \\
\text { Code }\end{array}$ \\
\hline \multicolumn{5}{|l|}{ Brain-related } \\
\hline Brain compression & $0(0)$ & $416(26)$ & $416(11)$ & G93.5 \\
\hline Intracerebral haemorrhage & $335(14)$ & $1(<1)$ & $336(8)$ & 161 \\
\hline Intracranial haemorrhage & $0(0)$ & $36(2)$ & $36(<1)$ & 162.9 \\
\hline Other and unspecified injuries of head & $0(0)$ & $36(2)$ & $36(<1)$ & S09 \\
\hline Stroke & $27(1)$ & $0(0)$ & $27(<1)$ & 164 \\
\hline Intracranial injury & $13(1)$ & $0(0)$ & $13(<1)$ & S06 \\
\hline Chronic obstructive pulmonary disease & $45(2)$ & $1(<1)$ & $46(1)$ & $\mathrm{J} 44$ \\
\hline Cardiac arrhythmias, unspecified & $35(1)$ & $0(0)$ & $35(<1)$ & 149.9 \\
\hline Heart failure & $31(1)$ & $2(<1)$ & $33(<1)$ & 150 \\
\hline Pulmonary oedema & $29(1)$ & $2(<1)$ & $31(<1)$ & J81 \\
\hline Aortic aneurysm and dissection & $13(<1)$ & $1(<1)$ & $14(<1)$ & 171 \\
\hline \multicolumn{5}{|l|}{ Infection-related } \\
\hline Septic shock & $380(16)$ & $148(9)$ & $528(13)$ & $\mathrm{R} 57.2$ \\
\hline Sepsis, unspecified & $29(<1)$ & $0(0)$ & $29(<1)$ & A41.1 \\
\hline Nosocomial condition & $14(<1)$ & $0(0)$ & $14(<1)$ & Y95 \\
\hline Unspecified & $149(6)$ & $1(<1)$ & $150(4)$ & NA \\
\hline Hypovolemic shock & $48(2)$ & $63(4)$ & $111(3)$ & R57.1 \\
\hline Intentional chemical self-poisoning & $101(4)$ & $0(0)$ & $101(3)$ & $x 60-9$ \\
\hline Gastrointestinal haemorrhage & $92(4)$ & $0(0)$ & $92(2)$ & K92.2 \\
\hline Hepatic failure & $48(2)$ & $0(0)$ & $48(1)$ & K72 \\
\hline Shock, not elsewhere classified & $26(1)$ & $4(<1)$ & $30(1)$ & R57 \\
\hline Respiratory distress in newborn & $28(1)$ & $0(0)$ & $28(1)$ & P22 \\
\hline $\begin{array}{l}\text { Other disorders of electrolyte and fluid balance, } \\
\text { not elsewhere classified }\end{array}$ & $18(1)$ & $0(0)$ & $18(1)$ & E87.8 \\
\hline $\begin{array}{l}\text { Post-procedural respiratory disorders, not } \\
\text { elsewhere classified }\end{array}$ & $0(0)$ & $12(1)$ & $12(<1)$ & J95 \\
\hline Total & $2340(100)$ & $1616(100)$ & $3956(100)$ & \\
\hline
\end{tabular}

ICD, International Statistical Classification of Diseases; NA, not applicable.

\section{Injury-related deaths}

The MoH reports confirm injury is a substantial cause of deaths in Viet Nam, particularly in the major cities. ${ }^{19}$ In 2011, the MoH reported that about one million Vietnamese people suffered some form of traffic injury or death each year. Road traffic accidents are the leading cause of death of 15-59-year-olds in Viet Nam, with VA studies suggesting they are the second most frequent cause of death in men and the fifth in women among the total population. ${ }^{19}$ A $2008 \mathrm{MoH}$ report stated that about 15000 people die as a result each year. ${ }^{20}$ Although this study described the immediate cause of death with more 
Table 3 Characteristics of patients discharged home compared to pre- and in-hospital deaths (May 2013 to March 2015)

\begin{tabular}{|c|c|c|c|c|c|c|}
\hline & \multicolumn{3}{|c|}{ Imminent deaths discharged home } & \multicolumn{3}{|c|}{ Deaths before reaching or in hospital } \\
\hline & $\begin{array}{l}\text { Bach Mai } \\
\text { Frequency (\%) }\end{array}$ & $\begin{array}{l}\text { Viet Duc } \\
\text { Frequency (\%) }\end{array}$ & $\begin{array}{l}\text { Total } \\
\text { Frequency (\%) }\end{array}$ & $\begin{array}{l}\text { Bach Mai } \\
\text { Frequency (\%) }\end{array}$ & $\begin{array}{l}\text { Viet Duc } \\
\text { Frequency (\%) }\end{array}$ & $\begin{array}{l}\text { Total } \\
\text { Frequency (\%) }\end{array}$ \\
\hline \multicolumn{7}{|l|}{ Gender } \\
\hline Male & $784(68)$ & $1138(77)$ & $1922(73)$ & $791(67)$ & $87(81)$ & $878(68)$ \\
\hline Female & 369 (32) & $348(23)$ & 717 (27) & $394(33)$ & $20(19)$ & $414(32)$ \\
\hline \multicolumn{7}{|l|}{ Age } \\
\hline Under 28 days & $1(<1)$ & $1(<1)$ & $2(<1)$ & $45(4)$ & $0(0)$ & $45(3)$ \\
\hline Under 5 years & $0(0)$ & $18(1)$ & $18(1)$ & 37 (3) & $1(<1)$ & 38 (3) \\
\hline $5-14$ years & $2(<1)$ & $28(2)$ & $30(1)$ & $7(<1)$ & $4(4)$ & $11(1)$ \\
\hline $15-34$ years & $137(12)$ & 509 (34) & $646(25)$ & $96(8)$ & $45(42)$ & $141(11)$ \\
\hline $35-59$ years & $554(48)$ & $604(41)$ & $1158(44)$ & $364(31)$ & $40(37)$ & $404(31)$ \\
\hline $60-74$ & $300(26)$ & $195(13)$ & 495 (19) & $338(29)$ & $9(8)$ & 347 (27) \\
\hline $75-90$ & $158(14)$ & $107(7)$ & $265(10)$ & $258(22)$ & $8(7)$ & $266(21)$ \\
\hline $90+$ & $7(1)$ & $17(1)$ & $24(1)$ & $34(3)$ & $0(0)$ & $34(3)$ \\
\hline Unknown & $2(<1)$ & $7(1)$ & $9(<1)$ & $8(<1)$ & $0(0)$ & $8(<1)$ \\
\hline \multicolumn{7}{|c|}{ Operation in last 4 weeks } \\
\hline Yes & $15(1)$ & $444(30)$ & 459 (17) & $30(3)$ & $22(21)$ & $52(4)$ \\
\hline No & $1138(99)$ & $1042(70)$ & $2180(83)$ & $1155(97)$ & $85(79)$ & $1240(96)$ \\
\hline Unknown & $0(0)$ & $0(0)$ & $0(0)$ & $0(0)$ & $0(0)$ & $0(0)$ \\
\hline \multicolumn{7}{|c|}{ Death related to injury/accident } \\
\hline Yes & $77(7)$ & $1097(74)$ & $1174(45)$ & $56(5)$ & $84(79)$ & $140(11)$ \\
\hline No & $1076(93)$ & $384(26)$ & $1460(55)$ & 1127 (95) & $23(21)$ & $1150(89)$ \\
\hline Unknown & $0(0)$ & $5(<1)$ & $5(<1)$ & $2(<1)$ & $0(0)$ & $2(<1)$ \\
\hline Total & $1153(100)$ & $1486(100)$ & 2639 (100) & $1185(100)$ & $107(100)$ & $1292(100)$ \\
\hline
\end{tabular}

specificity using ICD-10 coding (Level 3) than previous records using VA methods, the substantial number of deaths resulting from traffic accidents identified in VA data was reflected in the hospital death report form data captured from Viet Duc Hospital. Worldwide, the main type of injury associated with traffic-related incidents is traumatic brain injury. ${ }^{21}$ Our study similarly identified traumatic cerebral oedema as the most common injury-related condition associated with death reported in Viet Duc hospital $(37 \%, 555 / 1486)$. There were no such deaths recorded at Bach Mai hospital, as trauma patients are directed to Viet Duc. The economic burden of patients suffering traffic injuries is substantial with treatment costs consuming up to 6 months of average salary. ${ }^{22}$ Ability to pay may also be a factor for the high percentage of people discharged home to die after involvement in a traffic accident. ${ }^{22}$ These data reinforce the need to implement countermeasures to ameliorate fatalities and injuries resulting from traffic accidents in Viet Nam.

\section{Limitations and challenges}

The major limitation in this study related to the experience of the participating doctors in completing the death report forms. New doctors joined the hospitals after the training sessions and many would not have received training in completing the ICD-10 codes. This
Table 4 Immediate causes of death diagnosed for people discharged home to die (May 2013 to March 2015)

$\begin{array}{lll}\text { Bach Mai } & \text { Viet Duc } & \text { Total } \\ \text { Frequency } & \text { Frequency } & \text { Frequency } \\ (\%) & (\%) & (\%)\end{array}$

Causes of death

\begin{tabular}{|c|c|c|c|}
\hline $\begin{array}{l}\text { Traumatic } \\
\text { cerebral oedema }\end{array}$ & $0(0)$ & $555(37)$ & $555(21)$ \\
\hline $\begin{array}{l}\text { Brain } \\
\text { compression }\end{array}$ & $0(0)$ & 409 (28) & 409 (15) \\
\hline Septic shock & $233(20)$ & $105(7)$ & 338 (13) \\
\hline $\begin{array}{l}\text { Intra-cerebral } \\
\text { haemorrhage }\end{array}$ & $234(20)$ & $0(0)$ & $234(9)$ \\
\hline $\begin{array}{l}\text { Intentional } \\
\text { self-poisoning }\end{array}$ & $99(9)$ & $0(0)$ & $99(4)$ \\
\hline Pneumonia & $79(7)$ & $1(<1)$ & $80(3)$ \\
\hline Cerebral infarction & $55(5)$ & $3(<1)$ & $58(2)$ \\
\hline $\begin{array}{l}\text { Gastrointestinal } \\
\text { bleeding }\end{array}$ & $56(5)$ & $0(0)$ & $56(2)$ \\
\hline $\begin{array}{l}\text { Hypovolemic } \\
\text { shock }\end{array}$ & $1(<1)$ & $53(4)$ & $54(2)$ \\
\hline $\begin{array}{l}\text { Deaths from other } \\
\text { causes }\end{array}$ & 396 (34) & $360(24)$ & 756 (29) \\
\hline tal & $1153(100)$ & 1486 (100) & 2639 (100) \\
\hline
\end{tabular}


Table 5 Activities undertaken when injured (May 2013 to March 2015)

\begin{tabular}{|c|c|c|c|c|}
\hline Activity when injured & ICD-10 Code & $\begin{array}{l}\text { Bach Mai } \\
\text { Frequency (\%) }\end{array}$ & $\begin{array}{l}\text { Viet Duc } \\
\text { Frequency (\%) }\end{array}$ & $\begin{array}{l}\text { Total } \\
\text { Frequency (\%) }\end{array}$ \\
\hline \multicolumn{5}{|l|}{ Traffic-related injury } \\
\hline Pedestrian & V01-09 & $0(0)$ & $123(10)$ & $123(9)$ \\
\hline Push bike & V10-19 & $0(0)$ & $80(7)$ & $80(6)$ \\
\hline Falling & W00-W19 & $4(3)$ & $94(8)$ & $98(7)$ \\
\hline Accident at work & W00-X59 & $3(2)$ & $64(5)$ & $67(5)$ \\
\hline Accident at home & W00-X59 & $1(1)$ & $60(5)$ & $61(5)$ \\
\hline Assaulted/murdered & X85-Y09 & $0(0)$ & $21(2)$ & $21(2)$ \\
\hline
\end{tabular}

ICD, International Statistical Classification of Diseases.

gap was confirmed by the retrospective medical record review undertaken to check for accuracy and completeness of the death report forms, which identified incomplete recording of underlying causes of death. Resources such as autopsy, pathology, imaging and prior medical histories are not routinely available to doctors in Viet Nam. A diagnosis of immediate cause of death therefore would often be confined to physical examination, medical records and information from families. The data were only captured from hospital presentations, thereby excluding people who die in the community without presenting to a hospital. While patients discharged home to die were generally those for whom death was imminent, it is possible that these patients could subsequently be admitted to another hospital. In this study, patient IDs were checked as part of the analysis to identify duplicates, and this would be necessary if implemented at a national level. Doctors also reported challenges in using the ICD-10 coding system, which limited our ability to capture accurate data on underlying causes of death in particular. In this study, at the start of the project we trained only senior doctors, but there was no assessment of the extent to which this training was cascaded to their teams and the quality of the information passed on. Also, new doctors who joined during the study period did not receive formal training. We identified a need for additional and regular formal training sessions to ensure that all doctors receive the necessary training in ICD-10 coding.

The high volume of patients discharged home to die created additional complexity in relation to complete medical information being available in a timely way. ${ }^{5} 10$ This is the first time discharged home to die data has been collected. Predicting the time of deaths once discharged was often challenging. Further work is required to identify strategies to verify cause of death information for those discharged home to die. A high number of unspecified causes of death were noted, particularly at Bach Mai hospital. This may have been the result of patients dying on the way to hospital or in the hospital before information was available to make a diagnosis. Some of these cases may have been a result of the challenges experienced by the participating doctors in ascertaining cause of death or knowing how to complete the death report form for some patients. As the study was limited to two major urban hospitals, these findings are not necessarily generalisable to other hospitals in Viet Nam and the report form requires piloting at other types of hospitals before national implementation.

\section{CONCLUSION}

This study demonstrates that Vietnamese hospitals are able to implement a hospital death report form system that meets international standards. A total of 3956 deaths were recorded at two different, major hospitals, which for the first time identify the major causes of deaths. The reports provide information for the first time about causes of deaths for those discharged home to die that are of relevance for countries where this is a cultural preference. The $\mathrm{MoH}$ is planning to enhance the death report form system in Viet Nam by piloting the new WHO modified death report form in other hospitals and moving towards replacing the current national Government death form with the WHO modified death report form.

\section{Handling editor Seye Abimbola}

Funding This work was funded by the Australian Government Public Sector Linkages Program AusAID. Grant number: ROU62149. Project title:

"Improving Hospital Death Data Collection in Vietnam".

\section{Competing interests None declared.}

Ethics approval Ethics approval was obtained from the University of Sydney and the two hospitals in Viet Nam (Bach Mai Hospital and Viet Duc Hospital). 
Provenance and peer review Not commissioned; externally peer reviewed.

Data sharing statement No additional data are available.

Open Access This is an Open Access article distributed in accordance with the Creative Commons Attribution Non Commercial (CC BY-NC 4.0) license, which permits others to distribute, remix, adapt, build upon this work noncommercially, and license their derivative works on different terms, provided the original work is properly cited and the use is non-commercial. See: http:// creativecommons.org/licenses/by-nc/4.0/

\section{REFERENCES}

1. Swift B, West K. Death certification: an audit of practice entering the 21st century. J Clin Pathol 2005;5:275-9.

2. Choprapawon C, Porapakkham Y, Sablon O, et al. Thailand's national death registration reform: verifying the causes of death between July 1997 and December 1999. Asia Pac J Public Health 2005:17:110-16.

3. Sibai AM. Mortality certification and cause-of-death reporting in developing countries. Bull World Health Organ. 2004;82:83.

4. Lakkireddy D, Gowda MS, Murray CW, et al. Death report certificate completion: how well are physicians trained and are cardiovascular causes overstated? Am J Med 2004;117:492-8.

5. Johansson LA, Westerling R. Comparing hospital discharge records with death report certificates: can the differences be explained? $J$ Epidemiol Community Health 2002;56:301-8.

6. Mahapatra P, Shibuya K, Lopez AD, et al. Civil registration systems and vital statistics: successes and missed opportunities. Lancet 2007;370:1653-63.

7. World Health Organization. Mortality: guidelines for certification and rules for coding. Geneva, Switzerland: International Statistical Classification of Diseases and Health Related Problems Tenth Revision: Instruction Manual, 1993. http://www.who.int/ classifications/icd//CD10Volume2_en_2010.pdf (retrieved 2 February 2016).

8. Ministry of Health. Vietnam health information system review and assessment: report submitted to the Health Metrics Network, World Health Organization. Hanoi: Vietnamese Government, 2006:1-80.
9. World Health Organization. Global Health Observatory (GHO). Geneva: World Health Organisation, 2014; http://www.who.int/entity/ gho/countries/vnm/enhttp://www.who.int/entity/gho/countries/vnm/en

10. Soleman N, Chandramohan D, Shibuya K. Verbal Autopsy: current practices and challenges. Bull World Health Organ 2006;84:239-45.

11. Rao C, Osterberger B, Anh TD, et al. Compiling mortality statistics from civil registration systems in Viet Nam: the long road ahead. Bull World Health Organ 2010;88:58-65.

12. General Statistics Office of Vietnam. General Statistics Office of Vietnam, 2012. Hanoi: Vietnamese Government, 2012 [December 2014]; http://www.gso.gov.vn/default_en.aspx?tabid=503\&time=\&kw $=$ mortality

13. Huong DL, Minh HV, Byass P. Applying verbal autopsy to determine cause of death in rural Vietnam. Scand J Public Health 2003;31 (Suppl. 62):19-25.

14. Kalter HD, Gray RH, Black RE, et al. Validation of postmortem interviews to ascertain selected causes of childhood death in children. Int J Epidemiol 1990;19:380-86.

15. Huong DL, Minh HV, Urban J. Socio-economic status inequality and major causes of death in adults: a 5 year follow-up study in rural Vietnam. Public Health 2006;120:497-504.

16. Ngo AH, Rao RC, Hoa NP, et al. Mortality Patterns in Vietnam 2006 findings from a national verbal autopsy survey. BMC Research Notes 2010;3:78.

17. Walton M, Esguerra E, Duong DV, et al. Improving hospital death data collection in Viet nam: Final report 31 March 2015. Report to DFAT 2015, Commonwealth of Australia.

18. General Statistics Office of Vietnam 2010. Sex Ratio at Birth. http:// www.gso.gov.vn (retrieved 3 November 2015).

19. Chinh ND, Lap CD, Hiep ND, et al. Preliminary results of injury surveillance at Viet Duc Hospital. The Thai Journal of Surgery. 2007;28:83-9.

20. Administration of Preventive Medicine, Ministry of Health. Injury Mortality Statistics in 2008. In: Medicine AoP, ed. Hanoi: Ministry of Health Vietnam, 2009

21. Nguyen TL, Nguyen TH, Morita $S$, et al. Injury and pre-hospital trauma care in Hanoi Vietnam. Injury Int J Care Injured 2008;39:1026-33.

22. Nguyen $\mathrm{H}$, Ivers $\mathrm{RQ}$, Jan $\mathrm{S}$, et al. The economic burden of road traffic injuries: evidence from a provincial hospital in Vietnam. Injury Prev 2012;19:9-84 